\title{
Can elder-solicated advice be made more helpful for inquiring younger people?
}

\author{
Herbert Y. Reynolds ${ }^{1 *}$, Thomas S. Davis ${ }^{2}$ and Lisa D. Sevison ${ }^{1}$ \\ ${ }^{1}$ Department of Medicine, Penn State Milton S. Hershey Medical Center, Hershey PA, USA \\ ${ }^{2}$ Emeritus Faculty, Penn State College of Medicine, Hershey PA, USA
}

\begin{abstract}
Our breakfast group, which includes a variety of talented, professional leaders, including health care providers, we to delve into current societal topics and formulate approaches or suggest solutions. This perspective focuses on how elder-advice might be made more helpful to younger inquirers, often family members. For the elder: listen well and help the younger inquirers to develop confidence for inte1viewing, encourage them to practice presenting their strengths realistically, continue to explore multiple but suitable career choices, and be willing to critique their plans.
\end{abstract}

Our biweekly breakfast group likes to discuss current and controversial societal topics and then formulate approaches and solutions for improving them. This group of older persons - elders is a mixture of business executives, leaders of philanthropic charitable societies, medical practitioners, hospital administrators, investment bankers, and educators. As thoughtful insight is provided for a variety of life's situations, one wants to capture some of this wisdom and pass along this collective approach. But how best to do this? The intent of this perspective is to explore how giving elder advice might be relayed and made more helpful for younger inquirers.

Members of our group say they are often asked for career-related advice. The spectrum of advice seekers usually includes young people who may be family members, sometimes grandchildren. Among these advice-seekers may be those who are weighing next steps in junior business executive positions, including the evaluation of educational opportunities that may be encouraged, or now required, such as online degree programs. Those already in pre-professional medical training may wish to do volunteer mission-kind of service for an introduction into giving health care [1]. A more over inquiry may be for advice on how to prepare better for an interview and present oneself to greatest advantage. Although there are resources that provide free advice from elders, who give advice on a wide variety of topics that target younger people, known as the Elder Wisdom Circle [2], our group's individuals also wish to offer personal advice, which can be a challenge to give.

Our group has been impressed that other colleagues, also experienced and articulate elders, might not know how best to begin when confronted with beginning an interaction with an inquirer and getting started with offering advice. The initial interaction that prompts asking an elder for advice or an opinion might be casual and informal, and is different from the kind of request that might be asked of a person who is already serving as one's teacher, coach, or mentor. This role as an advisor is somewhat different from being a mentor, which implies more involvement and assistance with managing an academic career with research requirements, teaching assignments, and delivery of health care [3]. We collectively discussed "getting started" and identified some items for thought. As we authors have more experience advising those ultin 1ately interested in a medical care career, we will focus our advice in this direction.

First, on the receiving side for the young people who inquire, some variables exist such as: age - span, nature of the relationship with the elder consultant, perceived urgency for advice, or only superficial interest. This request may begin casually or be subtle, and thus be overlooked and ignored. Most important for the elderadvisor is to listen well and be attentive. Any advice tllen offered should be discerning, focused, and sagacious. Any offered must be well reasoned, perhaps rehearsed, and given succinctly. Always pass along information in an honest and efficient manner. Next, an advisor should assess if the inquirer displays appropriate confidence. Does the need to get advice and help seem to reflect the seeker's anxiety or feeling of discouragement? If so, the advisor might counsel to take a "rest" and get refocused to regain more confidence. Having the correct amount of self-confidence can be critical [4]; males may be overconfident and females tend to be under confident. An advisor should ask the inquirer if he/ she can articulately describe the special "dependable strengths" which one is always confident of possessing and demonstrating for others. How good is one's self-portrait, or selfie, that can be shared? Perhaps, a well-constructed verbal description of oneself might provide a more positive and realistic view that has greater impact? "What will be my "reception" after an interview, and how might this be improved?"

Helping to choose a career path is often an important factor, especially if the advice-seeker does not already have clear work or career goals. An advisor should try to lead a person in a direction that is suitable to consider but might require other educational experiences. Advice then might be directed towards keeping minds open to explore several career opportunities. For example, if one is exploring a job or

Correspondence to: Herbert Y. Reynolds, Emeritus Professor, Department of Medicine, Division of Pulmonary, Allergy and Critical Care Medicine, Penn State Milton S. Hershey Medical Center, Hershey PA, Penn State College of Medicine, Hershey PA, USA, E-mail: hreynolds@pennstatehealth.psu.edu

Received: May 29, 2017; Accepted: June 16, 2017; Published: June 19, 2017 
already working for a business, one should be advised to investigate its mission thoroughly, so one can buy into that company's value system and be willing to defend it. If it becomes evident to the advisor that candid information needs to be given that might necessitate trampling on someone's toes, soften the advice, if possible, and always be courteous.

For many young people, intrigue with science begins early in life, especially if there is a family tradition and parents or relatives are involved already. This interest in science might be reinforced after participating in a summer research program and later solidified by a college experience. Don't get diverted and lose focus of possible career goals. One way to further one's vision and explore another educational experience, is to read voraciously to expand one's horizons and to accumulate knowledge on a variety of subjects. This approach is invaluable, and will contribute to confidence.

For advanced training in health care careers, seeing patients in a variety of locations and situations, including in-hospital, hospital outpatient clinics, or on elective special volunteer missions, creates experience by managing similar illnesses cared for in different surroundings. These valying circumstances can help solidify the approach to health problems and further adapt the use of information and techniques [5]. Thus, getting experience in a new career, doing similar work but in different localities or for different purposes might be a suggestion given by a senior advisor to help allay anxiety in the beginning of a new job or career.
Hopefully with proper encouragement from family, colleagues, and others, such as "elder-advisors," a sequence for building confidence will evolve. Our results indicate that many can be funneled successfully into higher education and professional careers. The wish from our breakfast group is that elder advisors might be more helpful by providing good advice for those who ask for it.

\section{Funding disclosure}

$$
\text { None }
$$

\section{Conflicts of interest}

\section{None}

\section{Acknowledgments}

The authors appreciate the input and suggestions from other members of the breakfast group. Preparation of the manuscript by Ms. Lisa Sevison is appreciated.

\section{References}

1. Reynolds HY (2008) In choosing a research health career, mentoring is essential. Lung 86: 1-6.

2. www.elderwisdomcircle.org//

3. Reynolds HY (2007) Mentoring. Nurturing clinical and physician scientists in an academic career. The Pharos of Alpha Omega Alpha Honor Medical Society 70: 26-28.

4. Brooks D (2017) The Problem of Confidence. The New York Times p:A19.

5. Reynolds HY (2014) As the medical education curriculum is changing, it is still good to train students and physicians in many different locations. Lung 192: 829-832.

Copyright: $₫ 2017$ Reynolds HY. This is an open-access article distributed under the terms of the Creative Commons Attribution License, which permits unrestricted use, distribution, and reproduction in any medium, provided the original author and source are credited. 